\title{
The 6-min walking distance: long-term follow up in patients with COPD
}

\author{
C. Casanova*, ${ }^{*}$ C.G. Cote ${ }^{\uparrow}$, J.M. Marin ${ }^{+}$, J.P. de Torres*, A. Aguirre-Jaime*, \\ R. Mendez ${ }^{\S}$, L. Dordelly ${ }^{\uparrow}$ and B.R. Celli ${ }^{f}$
}

ABSTRACT: The 6-min walking distance (6MWD) test is used in clinical practice and research into patients with chronic obstructive pulmonary disease (COPD). However, little is known about natural long-term change in this parameter.

The 6MWD was measured at baseline and then annually for 5 yrs in 294 patients with COPD and its annual rate of decline was determined. Forced expiratory volume in one second (FEV1) was also measured and the relationship between changes in both markers was explored.

At baseline, the median 6MWD was $380 \mathrm{~m}$ (range 160-600 m). It declined by $19 \%\left(16 \mathrm{~m} \cdot \mathrm{yr}^{-1}\right.$ ) over the 5 yrs compared with baseline in patients with American Thoracic Society/European Respiratory Society stage III COPD (FEV $130-50 \%$ predicted) and by $26 \%\left(15 \mathrm{~m} \cdot \mathrm{yr}^{-1}\right.$ ) in patients with stage IV COPD (FEV $1<30 \%$ pred). Over the 5 -yr follow-up, the proportion of patients with a minimal clinically significant decline of $54 \mathrm{~m}$ increased with the severity of the disease. It was $24 \%$ in stage II, $45 \%$ in stage III, and $63 \%$ in stage IV disease. In contrast, the rate of decline of FEV 1 was greater in patients with milder airflow obstruction and lesser in patients with lower absolute FEV1 values.

In conclusion, the 6-min walking distance test provides increasingly useful information as the severity of chronic obstructive pulmonary disease increases.

KEYWORDS: Chronic obstructive pulmonary disease, 6-min walking distance

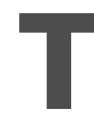

he 6-min walking distance (6MWD) test has gained importance in the assessment of functional exercise capacity in patients with chronic obstructive pulmonary disease (COPD) [1, 2] and other respiratory diseases, such as pulmonary hypertension [3], interstitial lung disease [4], cystic fibrosis [5] and post-acute respiratory distress syndrome [6]. The test evaluates the global and integrated responses of the pulmonary, cardiovascular and muscular component and reflects the functional exercise level for daily physical activities [7].

Introduced in 1976 as a 12-min walk test to measure the exercise capacity of patients with COPD, the abbreviated 6MWD has proved to be reliable, inexpensive, safe and easy to apply [710]. Furthermore, it correlates well with other important outcomes in COPD patients such as dyspnoea, airway obstruction and lung hyperinflation [11]. The test has been shown to be an important prognostic factor for outcome independent of the forced expiratory volume in one second (FEV1) [12]. The 6MWD is a submaximal excercise test, but it correlates well with the maximal cardiopulmonary exercise test [13-15], and appears to be better tolerated and more reflective of the activities of daily living than other walk tests [16, 17].

While there is plenty of data concerning the natural history of FEV1 over time, little information has been published regarding the temporal behaviour of the 6MWD. This is a significant omission, as the 6MWD test is frequently used to evaluate the long-term impact of interventions. Changes in 6MWD over time have been addressed in one published study [12], but it was limited to patients with severe COPD, the follow-up time was relatively short ( $1 \mathrm{yr}$ ) and the decline trend was established with only two measurements.

As part of the large body mass index, degree of obstruction, dyspnoea and exercise capacity (BODE) cohort, the present authors have evaluated the $6 \mathrm{MWD}$ systematically as one of several variables included in the evaluation of patients. Thus, subjects in the present study had a wide range of severity of COPD. The results are expressed both as absolute change and in terms of the reference equations derived for 6MWD in healthy populations $[18,19]$.

\section{AFFILIATIONS}

${ }^{*}$ Respiratory Research Institute, and

${ }^{\text {\#}}$ Pulmonary Dept, Hospital

Universitario La Candelaria, Tenerife, and

+Pulmonary Dept, Hospital Miguel Servet, Zaragoza, Spain

${ }^{\S}$ Pulmonary Dept, Hospital Jose I Baldo, Caracas, Venezuela.

-Pulmonary Dept, Bay Pines Veterans Affairs Medical Center, St Petersburg $\mathrm{FL}$, and

fPulmonary and Critical Care Dept, Caritas-St Elizabeth's Medical Center, Boston, MA, USA.

\section{CORRESPONDENCE}

C. Casanova

Universidad de La Laguna Respiratory Research Institute Pulmonary Dept

Hospital Universitario La Candelaria Carretera del Rosario s/n 38010-Santa Cruz de Tenerife Spain

Fax: 34922600562

E-mail: ccasanova@canarias.org

Received:

May 302006

Accepted after revision:

November 062006

STATEMENT OF INTEREST

None declared. 


\section{METHODS}

A total of 294 outpatients with COPD from the original BODE cohort [1] with a wide range of airflow obstruction, from clinics in the USA (Bay Pines Veterans Affairs Medical Center, Bay Pines, FL), Spain (Hospital Universitario La Candelaria, Tenerife, and Hospital Miguel Servet, Zaragoza), and Venezuela (Hospital Jose I Baldo, Caracas), participated in the study, which was approved by the human review boards at each centre. Patients were enrolled from December 1995 to September 2004 and had $\geqslant 3$ yrs follow-up time. After the initial 3 yrs, the cohort was followed up to 5 yrs. Deaths occurring during this time were confirmed by review of the records. COPD was defined by a smoking history of $>20$ packyrs and a post-bronchodilator FEV1/forced vital capacity $($ FVC $)<0.7$. Patients were clinically stable for $\geqslant 6$ weeks and were receiving optimal medical therapy according to current guidelines. Exclusion criteria were: uncontrolled comorbidities likely to affect mortality within $3 \mathrm{yrs}$, such as malignant disorders or cardiovascular disease; history of asthma; inability to perform the lung function and 6-min walk tests; and involvement in pulmonary rehabilitation.

After $\geqslant 6$ weeks of clinical stability, patients were tested with pulmonary function tests, spirometry and lung volume measurements according to American Thoracic Society guidelines [20]. The severity of the obstruction was classified using the Global Initiative for Chronic Obstructive Lung Disease (GOLD) and ATS/European Respiratory Society classification. All patients had an FEV1/FVC $<0.7$. Patients in stage I have an FEV1 $>80 \%$ predicted; stage II patients have an FEV1 $50-80 \%$ pred; stage III patients have an FEV1 $30-49 \%$ pred; and stage IV patients have an FEV1 $<30 \%$ pred.

The 6MWD was measured using the best of two 6-min walk tests separated by $\geqslant 30 \mathrm{~min}[1,7,21]$. The $6 \mathrm{MWD}$ was expressed in absolute values and as per cent pred using two published reference values [18, 19]. Inspiratory fraction, or ratio of inspiratory capacity (IC) to total lung capacity (TLC) was used as a measure of static lung hyperinflation [11]. The combined Charlson index was used to determine the degree of comorbidity [22]. Patients were re-evaluated every 12 months for $\geqslant 3$ yrs.

\section{Statistical analysis}

Qualitative variables are expressed as relative frequencies of categories. Numerical values are expressed as median (5th-95th percentile) because of their skewed distribution. Differences between groups were tested using the Chi-squared test for categorical variables or the Mann-Whitney U-test for numerical variables. Correlations were estimated using Spearman's rank coefficient. The slopes of 6MWD decline were estimated by means trend modelling based on median annual values, with $95 \%$ confidence intervals (CI). To estimate possible differences in progression owing to the differential loss between patients who dropped out and those who remained between 3 and 5 yrs, general linear modelling was performed for repeated measures. Significance was defined as a two-tailed p-value $<0.05$.

\section{RESULTS}

The cohort of 294 patients was distributed as follows: 200 (68\%) from the USA; 84 (29\%) from Spain (56 from Tenerife; 28 from
Zaragoza); and 10 (3\%) from Venezuela. Patient characteristics are presented in table 1 . The median age was 66 yrs (51$79 \mathrm{yrs})$, and the majority of subjects $(97 \%)$ were male. At the time of entry to the study, their disease states were as follows. GOLD and ATS/ERS stage I: $1 \%(n=4)$; stage II: $28 \%(n=81)$; stage III: $46 \%(n=136)$; stage IV: $25 \%(n=73)$.

After the initial 3 yrs and during the follow-up period, 194 patients were lost to the study. Of these losses, 69 were due to deaths and 125 due to other causes. No statistically significant difference in the 6MWD decline progression between those patients lost from the study and those who remained at 3 yrs (131 versus 163 patients) and 4 yrs follow-up time (63 versus 100 patients). However, compared with the survivors, those who died underwent a steeper 6MWD decline, of $25 \mathrm{~m} \cdot \mathrm{yr}^{-1}$ (95\% CI $\left.10-40 \mathrm{~m} \cdot \mathrm{yr}^{-1}\right)$.

The median (5th-95th percentile) 6MWD at baseline was $388 \mathrm{~m}$ (160-600 m). It declined by $12.5 \mathrm{~m} \cdot \mathrm{yr}^{-1}\left(95 \% \mathrm{CI} 8-17 \mathrm{~m} \cdot \mathrm{yr}^{-1}\right)$ for up to $5 \mathrm{yrs}(\mathrm{p}=0.001$; fig. 1$)$. The baseline $6 \mathrm{MWD}$ expressed as per cent pred using the equations of ENRIGHT and SHERRILL [18] and TROOSTERS et al. [19] were 75\% (47-99\%), and 58\% (39-77\%; fig. 2), respectively. Of note, 6MWD declined significantly only in patients with FEV $1<50 \%$ pred (fig. 3). In patients with GOLD and ATS/ERS stage III COPD, 6MWD decreased by $19 \%$ compared with baseline $\left(16 \mathrm{~m} \cdot \mathrm{yr}^{-1}\left(95 \% \mathrm{CI} 8-24 \mathrm{~m} \cdot \mathrm{yr}^{-1}\right) ; \mathrm{p}\right.$ $<0.006)$ and in patients with stage IV COPD it decreased by $26 \%$ compared with baseline $\left(15 \mathrm{~m} \cdot \mathrm{yr}^{-1}\left(95 \% \mathrm{CI} 7-22 \mathrm{~m} \cdot \mathrm{yr}^{-1}\right)\right.$; $\mathrm{p}=0.005)$. The decline did not reach statistical significance in patients with stage II COPD ( $2 \%$ compared with baseline; $6 \mathrm{~m} \cdot \mathrm{yr}^{-1}\left(95 \%\right.$ CI $\left.-4-16 \mathrm{~m} \cdot \mathrm{yr}^{-1}\right) ; \mathrm{p}=0.16$; fig. 4).

The rate of decline was not influenced by the age of the patients $\left(14 \mathrm{~m} \cdot \mathrm{yr}^{-1}\right.$ in patients aged $>65 \mathrm{yrs}$ and $13 \mathrm{~m} \cdot \mathrm{yr}^{-1}$ in patients aged $<65 \mathrm{yrs})$. The rate of decline was greater in

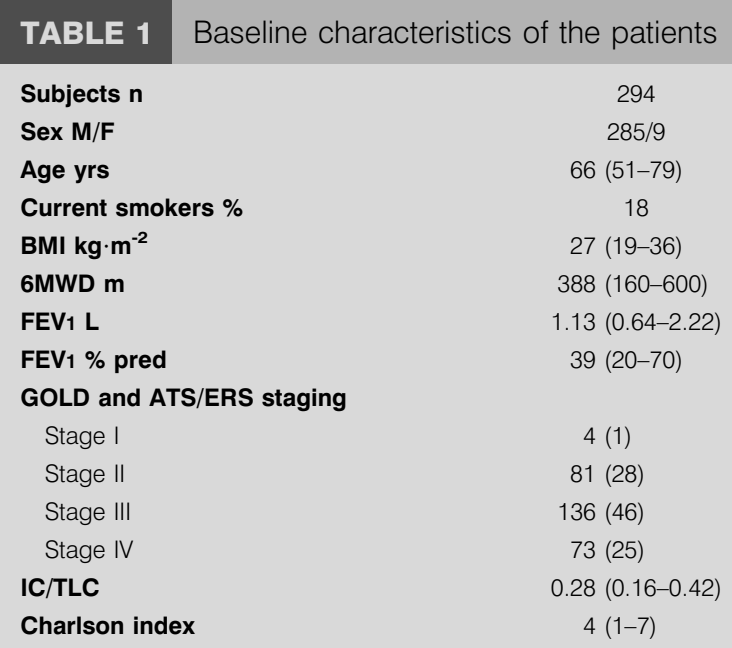

Data are presented as $n$, median (5th-95th percentile) or $n(\%)$, unless otherwise stated. M: male; F: female; BMI: body mass index; 6MWD: 6-min walking distance; FEV1: forced expiratory volume in one second; \% pred: \% predicted; GOLD: Global Initiative for Chronic Obstructive Lung Disease; ATS: American Thoracic Society; ERS: European Respiratory Society; IC: inspiratory capacity; TLC: total lung capacity. 


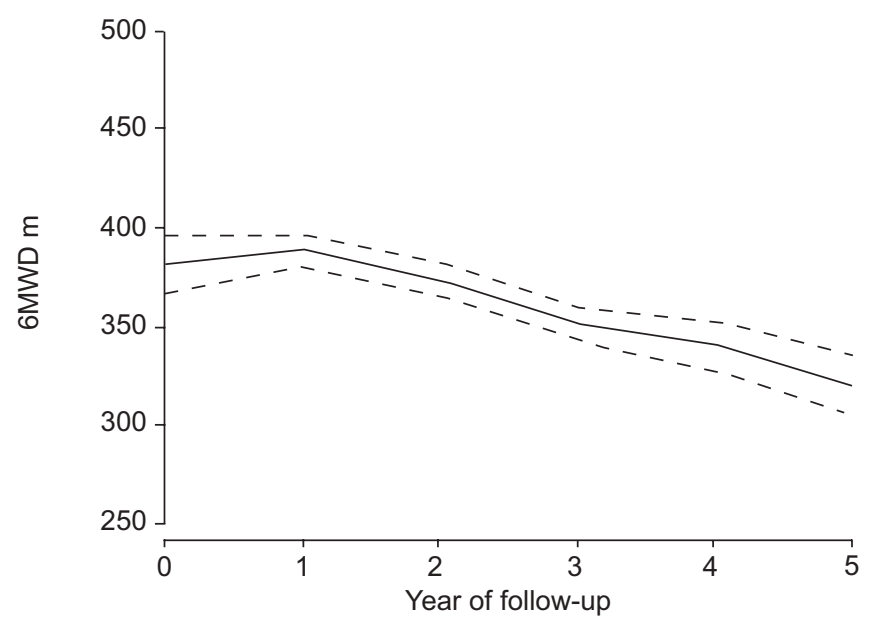

FIGURE 1. Median 6-min walking distance (6MWD) over 5 yrs. Baseline median (range) 6MWD was $388 \mathrm{~m}(161-600 \mathrm{~m} ; \mathrm{n}=294)$. It declined at $12.5 \mathrm{~m} \cdot \mathrm{yr}^{-1}$ (95\% confidence interval 8-17 $\left.\mathrm{m} \cdot \mathrm{yr}^{-1}\right)$ for up to $5 \mathrm{yrs}(\mathrm{p}=0.001)$. _ ------: 95\% confidence intervals. Year 4: $n=163$; year 5: $n=100$

patients from the USA $\left(14 \mathrm{~m} \cdot \mathrm{yr}^{-1} \quad\left(95 \%\right.\right.$ CI $\left.6-21 \mathrm{~m} \cdot \mathrm{yr}^{-1}\right)$; $\mathrm{p}=0.008)$ than in patients from the other regions $\left(7 \mathrm{~m} \cdot \mathrm{yr}^{-1}\right.$ $\left(95 \%\right.$ CI $\left.\left.0-15 \mathrm{~m} \cdot \mathrm{yr}^{-1}\right) ; \mathrm{p}=0.05\right)$. This is in agreement with the fact that patients from the USA had higher degrees of obstruction and comorbidity.

The proportion of patients with a minimal clinically significant decline $(\geqslant 54 \mathrm{~m})$ in $6 \mathrm{MWD}$ over the 5 -yr period increased with the severity of the disease (stage II: $24 \%$; stage III: $45 \%$; stage IV: $63 \% ; p=0.025)$.

Post-bronchodilator FEV1 values declined significantly, with a mean rate of decline of $23 \mathrm{~mL} \cdot \mathrm{yr}^{-1}\left(95 \%\right.$ CI $14-32 \mathrm{~mL} \cdot \mathrm{yr}^{-1}$; $\mathrm{p}=0.002)$. The decline differed by disease stage, in the opposite way to the $6 \mathrm{MWD}$ (fig. 4). FEV1 declined in stage II patients by $40 \mathrm{~mL} \cdot \mathrm{yr}^{-1}\left(95 \%\right.$ CI $\left.20-70 \mathrm{~mL} \cdot \mathrm{yr}^{-1} ; \mathrm{p}=0.011\right)$, whereas the fall was smaller in patients with stage III disease $\left(10 \mathrm{~mL} \cdot \mathrm{yr}^{-1}\right.$

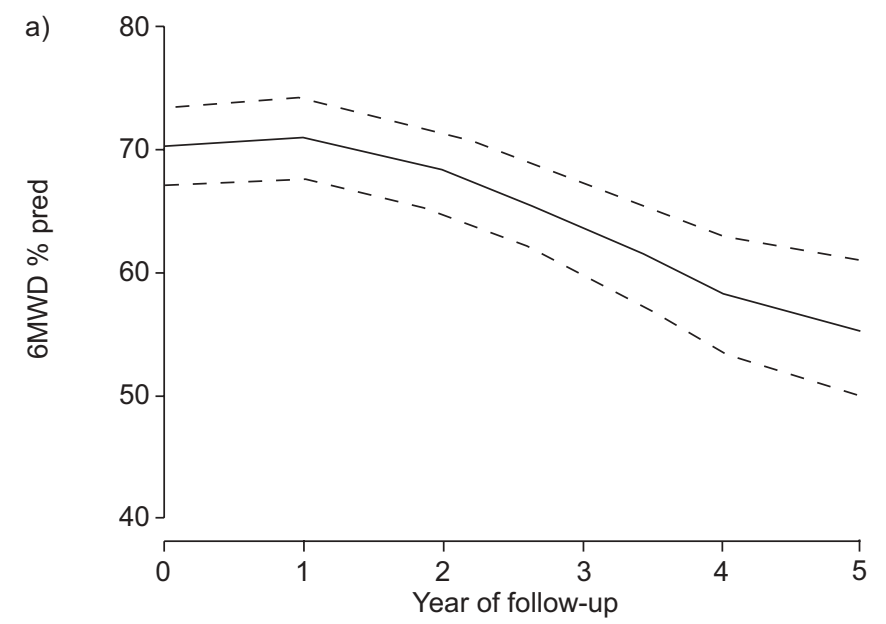

$\left.\left(95 \% \mathrm{CI} 4-20 \mathrm{~mL} \cdot \mathrm{yr}^{-1}\right) ; \mathrm{p}=0.017\right)$ and FEV1 did not decline in patients with stage IV COPD $(p=0.73)$. The pattern was similar when only patients who had been followed for 5 yrs were included in the analysis ( $\mathrm{n}=99$; stage II: $46 \mathrm{~mL} \cdot \mathrm{yr}^{-1}(95 \%$ CI 22$\left.70 \mathrm{~mL} \cdot \mathrm{yr}^{-1}\right), \mathrm{p}=0.006$; stage III: $31 \mathrm{~mL} \cdot \mathrm{yr}^{-1}(95 \%$ CI $-18-$ $\left.80 \mathrm{~mL} \cdot \mathrm{yr}^{-1}\right) \quad \mathrm{p}=0.158$; stage $\mathrm{IV}: 27 \mathrm{~mL} \cdot \mathrm{yr}^{-1} \quad(95 \%$ CI $1-$ $\left.\left.53 \mathrm{~mL} \cdot \mathrm{yr}^{-1}\right) \mathrm{p}=0.047\right)$.

IC/TLC did not change significantly over the period of study. There were no significant differences in comorbidity score between the different GOLD and ATS/ERS stages (stage II: 4 (5th-95th percentile 1-8); stage III: 4 (1-8); stage IV: 4 (1-7)). However, over time there was some worsening of comorbidity, with the Charlson score increasing from 4 (1-7) to $5(2-12$; $\mathrm{p}<0.001)$.

The characteristics of the cohort by region are presented in table 2. COPD patients from Spain walked more (463 m (336$635 \mathrm{~m})$ ) than those from the USA (350 m (146-503 m)). FEV1 was slightly lower and comorbidity was higher among patients from the USA than those from Spain. These variables partially explained the differences in 6MWD $\left(\mathrm{r}^{2}=0.36 ; \mathrm{p}<0.001\right)$. There was no difference in $6 \mathrm{MWD}$ between the patients from Tenerife, Zaragoza and Venezuela.

\section{DISCUSSION}

To the present authors' knowledge, this is the first prospective large long-term cohort study evaluating the temporal change of $6 \mathrm{MWD}$ in patients with COPD and a wide range of airflow obstruction. The most important finding is that the $6 \mathrm{MWD}$ declines over time, but that the decline is really significant only in patients with severe airflow limitation (FEV $1<50 \%$ pred). In addition, the decline worsened with disease severity. This contrasted with the rate of FEV1 loss over time, which was lower at the more severe stages of the disease.

The impairment of patients with COPD is more comprehensibly described if pulmonary function tests are complemented with an evaluation of exercise performance [2]. The latter is usually carried out via a cardiopulmonary test in a specialised

b)

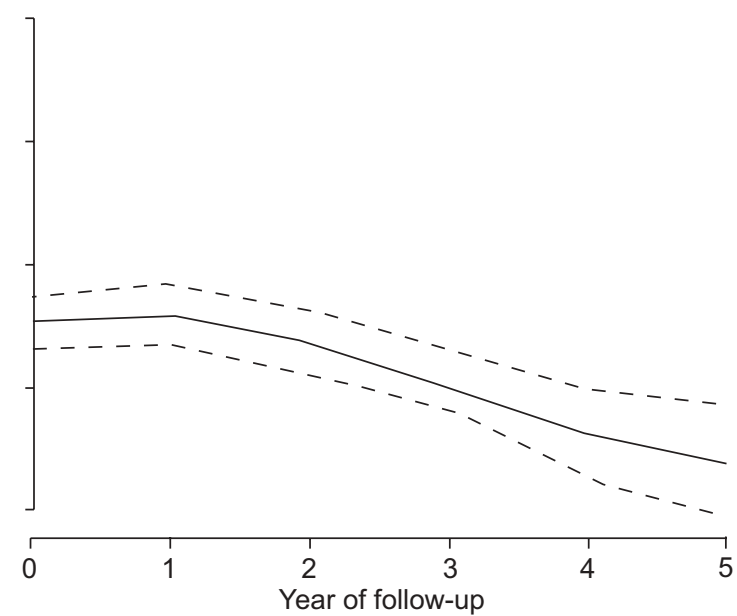

FIGURE 2. Change in 6-min walking distance (6MWD) over time as a percentage of the predicted values (\% pred) as reported by a) ENRIGHT and SHERRILL [18] (2.1\%.yr ${ }^{-1}$

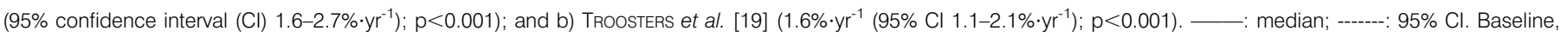
years 1-3: $n=294$; year $4: n=163$; year $5: n=100$. 


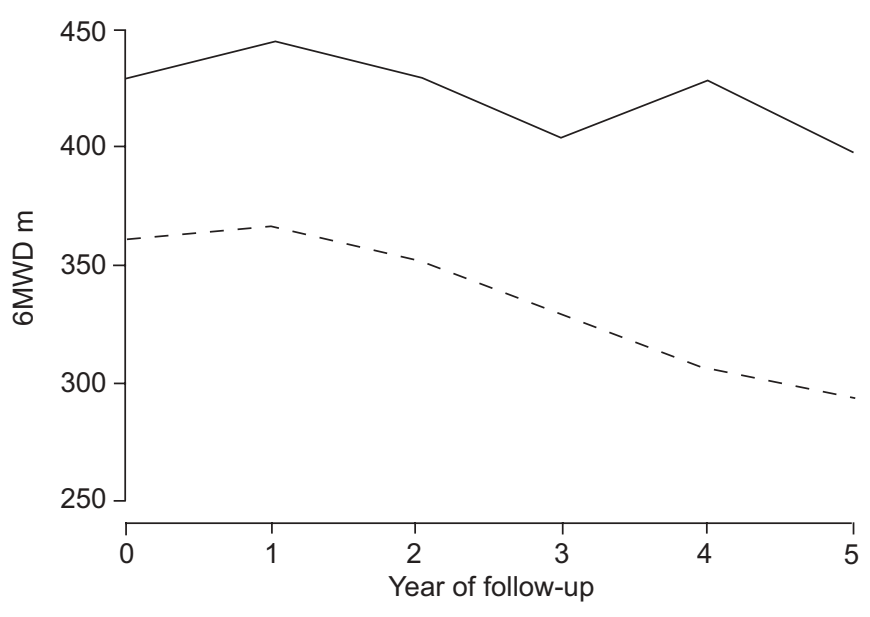

FIGURE 3. The 6-min walking distance (6MWD) declines significantly in patients with a forced expiratory volume in one second ( $\left.F E V_{1}\right)<50 \%$ predicted (------; $15.3 \mathrm{~m} \cdot \mathrm{yr}^{-1}$ (95\% confidence interval (Cl) 9.1-21.4 m·yr $\left.\left.\mathrm{r}^{-1}\right) ; \mathrm{p}=0.002\right)$. FEV $1>50 \%$ pred, years $0-3: n=85$; year $4: n=44$; year $5: n=25)$. $F E V_{1}<50 \%$ pred, years $0-3$ : $n=209$; year $4: n=119$; year 5 : $n=75$ ).

laboratory or, more commonly, in the field, using a timed walk test. Owing to its ease of administration and value as a predictor of functional capacity and mortality, the 6MWD has gained wide acceptance [12, 23]. Surprisingly, compared with the FEV1 $[24,25]$, there is very little information regarding the natural evolution of exercise capacity in general or the $6 \mathrm{MWD}$ more specifically, probably reflecting the belief that airflow obstruction represents the most important determinant of the natural history of COPD. Recently, OGA et al. [26], studying patients with COPD, have shown a progressive deterioration in exercise capacity over time when evaluated by maximal oxygen intake $\left(V^{\prime} \mathrm{O}_{2}\right.$, max $)$ during maximal cycle ergometry. OGA et al. [26] described a weak correlation between $V^{\prime} \mathrm{O}_{2}$, max and decline in FEV1. Interestingly, they observed a stronger

\begin{tabular}{|c|c|c|c|}
\hline \multirow[t]{2}{*}{ TABLE 2} & \multicolumn{3}{|c|}{$\begin{array}{l}\text { Characteristics of the cohort according to } \\
\text { country }\end{array}$} \\
\hline & USA & Spain & $\mathrm{p}$-value \\
\hline Subjects & 200 & 84 & \\
\hline Sex M/F & $193 / 7$ & $83 / 1$ & 0.443 \\
\hline Age yrs & $66(51-79)$ & $67(47-76)$ & 0.461 \\
\hline BMI $\mathbf{k g} \cdot \mathrm{m}^{-2}$ & $27(18-37)$ & 27 (19-36) & 0.658 \\
\hline 6MWD m & $350(146-503)$ & 463 (336-635) & $<0.001$ \\
\hline FEV 1 L & $1.20(0.6-2.1)$ & $1.15(0.6-2.3)$ & 0.946 \\
\hline FEV $1 \%$ pred & 37 (19-67) & $43(21-75)$ & 0.014 \\
\hline IC/TLC & $0.29(0.14-0.42)$ & $0.28(0.13-0.44)$ & 0.385 \\
\hline $\begin{array}{l}\text { Charlson } \\
\text { index }\end{array}$ & $4(2-8)$ & $2(1-6)$ & $<0.001$ \\
\hline
\end{tabular}

Data are presented as $\mathrm{n}$ or median (5th-95th percentile). M: male; $\mathrm{F}$ : female; BMI: body mass index; 6MWD: 6-min walking distance; FEV1: forced expiratory volume in one second; \% pred: \% predicted; IC: inspiratory capacity; TLC: total lung capacity.

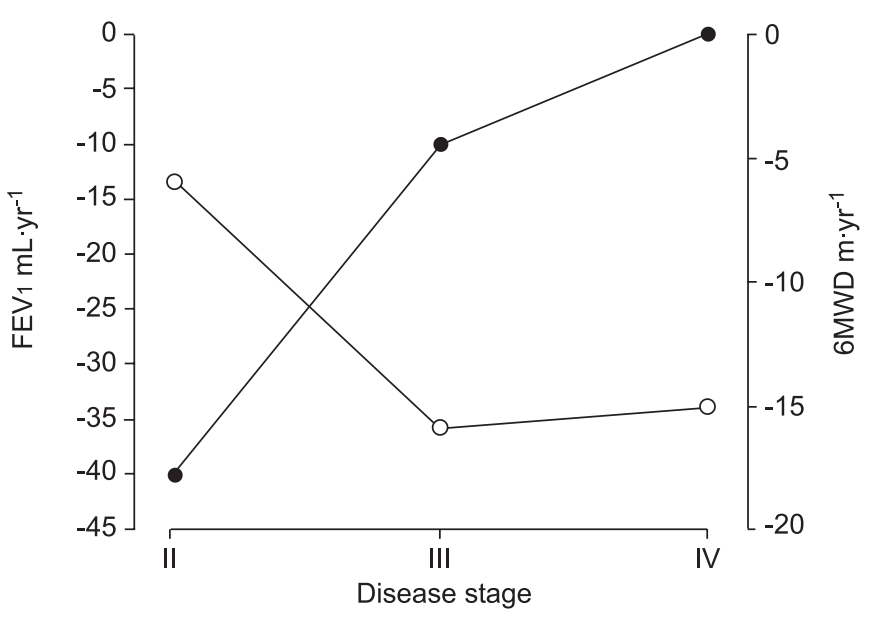

FIGURE 4. The decline in 6-min walk distance $(O)$ was greater in patients with more severe airflow obstruction, as determined by Global initiative for Chronic Obstructive Lung Disease and American Thoracic Society/European Respiratory Society staging criteria. In contrast forced expiratory volume in one second (FEV1; -) changed less in those patients with more severe airflow limitation. $\Delta$ : change. Stage II: $n=81$; stage III: $n=136$; stage IV: $n=73$.

correlation between $V^{\prime} \mathrm{O}_{2}$,max and the dynamic ventilatory constraints of dynamic hyperinflation, which in their patients progressed over time. They speculated that hyperinflation contributed to the longitudinal decline in exercise capacity. However, there was no adjustment for comorbidity, hence the involvement of other organs could have influenced their overall results. Similarly, the current authors did not observe an association between 6MWD decline and FEV1. However, no change in static hyperinflation, estimated by the rate of change of IC/TLC, was detected over the 5 yrs of the present study. The differences between the two studies may relate to methodology: OGA et al. [26] used a symptoms-limited exercise test and dynamic hyperinflation, whereas the present authors used the $6 \mathrm{MWD}$ and static hyperinflation. More studies using similar methodology may help resolve these differences.

After short-term interventions, such as 3 months' pulmonary rehabilitation, the estimated threshold for clinically significant change in the 6MWD is thought to be $\sim 50 \mathrm{~m}$ [27], but there is very limited information about the predicted decline over a longer period in COPD [12]. The present results show that the annual decline in 6MWD is relatively small, at $12.5 \mathrm{~m} \cdot \mathrm{yr}^{-1}$. The decline was low in patients with moderate obstruction, but larger in patients with FEV1 $<50 \%$ pred. In this group, the proportion of patients with changes in 6MWD greater than the minimal clinically important difference increased with increasing airflow obstruction (fig. 4). This is significant, because at that level of disease severity, the FEV1 behaves as a more rigid and less sensitive parameter to detect clinical changes. Thus, the present results can clarify the role of the 6MWD in the long-term evaluation of patients with COPD, with it being shown to be of most help when evaluating patients with FEV1 $<50 \%$ pred.

It is possible to speculate why the decline of the $6 \mathrm{MWD}$ is more manifest in patients with more severe airflow limitation. It could simply relate to the deconditioning brought about by a 
more sedentary lifestyle, as more severe COPD is associated with greater dyspnoea. However, it is also possible that the decline results from the development of more advanced systemic involvement of COPD [28]. This hypothesis is further supported by the observations of AGUSTI et al. [29], who showed worsening apoptosis in muscle biopsies of patients with COPD, and by MONTES DE OCA et al. [30] who described increased levels of markers of oxidative stress and infiltration by macrophages in patients with severe COPD compared with controls. In addition, worsening Charlson comorbidity scores over time in the present study suggest a possible role for increasing comorbidity as the population aged. Taken together, these findings can be clinically important, as the therapy could change depending upon the reason for the decline.

The mean annual decline of the 6MWD in the current study is smaller than that reported by PINTO-PLATA et al. [12] (26 $\left.\mathrm{m} \cdot \mathrm{yr}^{-1}\right)$. These differences may be explained by the fact that the present authors excluded patients who did not complete the first 3 yrs of follow-up. Therefore, the differences are probably due to the fact that PINTO-PLATA et al. [12] evaluated the decline in 6MWD in a population of severe COPD patients with a very low baseline 6MWD and high comorbidity, as evidenced by their high (27\%) short-term mortality. Indeed, in the current study, patients followed for 3 yrs who subsequently died during the follow-up period had a steeper rate of decline $\left(25 \mathrm{~m} \cdot \mathrm{yr}^{-1}\right)$, very close to that observed by PINTO-PLATA et al. [12]. Taken together, the results of both studies indicate that steep declines in 6MWD are indicative of poor prognosis and should raise concern regarding the wellbeing of the patient.

The current study also observed important variability in the expression of the results as per cent pred values derived from standard equations for healthy individuals $[18,19]$. This may be due to differences among the studies that generated the predictive equations in use. ENRIGHT and SHERRILL [18] generated the predicted equation using the values from only one 6MWD, and subjects were instructed to walk at their own pace rather than as quickly as possible. Conversely, the study by TROOSTERs et al. [19] was based on a smaller sample of healthy subjects and may not represent the general population at large. This suggests a need to develop new reference values with larger numbers and standard methodology.

The present study has some limitations. First, few females were included. This was not by design, because the opportunity to join the study was independent of sex. However, the large proportion of males may be seen as lending more validity to the findings, because they cannot be attributed to gender bias. Secondly, the current results do not wholly address the issue of individual patient variability, since 6MWD annual decline was interpreted as a mean value of the group. The actual change for an individual may be less or more than the mean and its importance can be judged only in the context of the specific situation in which it is measured.

In summary, the present study shows that the decline in 6-min walking distance over time is most important in patients with more severe obstruction. This contrasted with the smaller changes in forced expiratory volume in one second observed in those patients. The results also suggest that in the regular evaluation of patients with severe obstruction (measured by forced expiratory volume in one second), repeated measures of 6-min walking distance can help describe clinical changes that cannot be detected easily in the sequential evaluation of pulmonary impairment. These findings have to be taken into account when planning studies using changes in 6-min walking distance over time. In addition, the current study suggests that the 6-min walking distance is of greatest help in the evaluation of patients with severe airflow limitation.

\section{REFERENCES}

1 Celli BR, Cote C, Marin JM, et al. The body-mass index, airflow obstruction, dyspnea and exercise capacity index in chronic obstructive pulmonary disease. N Engl J Med 2004; 350: 1005-1012.

2 Celli BR, MacNee W, ATS/ERS Task Force, Standards for the diagnosis and treatment of patients with COPD: a summary of the ATS/ERS position paper. Eur Respir J 2004; 23: 932-946.

3 Miyamoto S, Nagaya N, Satoh T, et al. Clinical correlates and prognostic significance of 6 minute walk in patients with pulmonary hypertension. Comparison with cardiopulmonary exercise testing. Am J Respir Crit Care Med 2000; 161: 487-492.

4 Eaton T, Young P, Milne D, Wells AU. Six-minute walk, maximal exercise test: reproducibility in fibrotic interstitial pneumonia. Am J Respir Crit Care Med 2005; 171: 1150-1157.

5 Chetta A, Pisi G, Zanini A, et al. Six minute walking test in cystic fibrosis adults with mild to moderate lung disease: comparison to healthy subjects. Respir Med 2001; 95: 986-991.

6 Herridge MS, Cheung AM, Tansey CM, et al. One-year outcomes in survivors of the acute respiratory distress syndrome. N Engl J Med 2003; 348: 683-693.

7 ATS Committee on Proficiency Standards for Clinical Pulmonary Function Laboratories, ATS Statement: guidelines for the six-minute walk test. Am J Respir Crit Care Med 2002; 166: 111-117.

8 McGavin CR, Gupta SP, McHardy GRJ. Twelve minute walking test for assessing disability in chronic bronchitis. BMJ 1976; 1: 822-823.

9 Butland RJA, Pang J, Gross ER, Woodcock AA, Geddes DM. Two, six and 12-minute walking test in respiratory disease. BMJ 1982; 284: 1607-1608.

10 Enright PL, McBurnie MA, Bittner V, et al. The 6-min walk test: a quick measure of functional status in elderly adults. Chest 2003; 123: 387-398.

11 Casanova C, Cote C, de Torres JP, et al. Inspiratory-to-total lung capacity ratio predicts mortality in patients with chronic obstructive pulmonary disease. Am J Respir Crit Care Med 2005; 171: 591-597.

12 Pinto-Plata VM, Cote C, Cabral H, Taylor J, Celli BR. The 6min walk distance: change over time and value as a predictor of survival in severe COPD. Eur Respir J 2004; 23: 28-33.

13 Cahalin L, Pappagianopoulos P, Prevost S, Wain J, Ginns L. The relationship of the 6-min walk test to maximal oxygen consumption in transplant candidates with end-stage lung disease. Chest 1995; 108: 452-459.

14 Carter R, Holiday DB, Nwasuruba C, Stocks J, Grothues C, Tiep B. 6-minute walk work for assessment of functional capacity in patients with COPD. Chest 2003; 123: 1408-1415. 
15 Casas A, Vilaro J, Rabinovich R, et al. Encouraged 6-min walking test indicates maximum sustainable exercise in COPD patients. Chest 2005; 128: 55-61.

16 Solway S, Brooks D, Lacasse Y, Thomas S. A quantitative systematic overview of the measurement properties of functional walk test used in the cardiorespiratory domain. Chest 2001; 119: 256-270.

17 Pitta F, Troosters T, Spruit MA, Probst VS, Decramer M, Gosselink R. Characteristics of physical activities in daily life in chronic obstructive pulmonary disease. Am J Respir Crit Care Med 2005; 171: 972-977.

18 Enright PL, Sherrill DL. Reference equations for the sixminute walk in healthy adults. Am J Respir Crit Care Med 1998; 158: 1384-1387.

19 Troosters T, Gosselink R, Decramer M. Six minute walking distance in healthy elderly subjects. Eur Respir J 1999; 14: 270-274.

20 Lung function testing, selection of reference values and interpretative strategies. American Thoracic Society. Am Rev Respir Dis 1991; 144: 1202-1218.

21 Sciurba FC, Slivka WA. Six-minute walk-testing. Semin Respir Crit Care Med 1998; 9: 383-391.

22 Charlson M, Szatrowsky T, Peterson J, Gold J. Validation of a combined comorbidity index. J Clin Epidemiol 1994; 47: 1245-1251.

23 Hajiro T, Nishimura K, Tsukino M, Ikeda A, Koyama H, Izumi T. Comparison of discriminative properties among disease-specific questionnaires for measuring health-related quality of life in patients with chronic obstructive pulmonary disease. Am J Respir Crit Care Med 1998; 157: 785-790.
24 Pauwels RA, Buist AS, Calverley PM, Jenkins CR, Hurd SS. Global strategy for the diagnosis, management and prevention of chronic obstructive pulmonary disease. NHLBI/WHO Global Initiative for Chronic Obstructive Lung Disease (GOLD) workshop summary. Am J Respir Crit Care Med 2001; 163: 1256-1276.

25 Fletcher CM, Peto R, Tinker C, Speizer FE. The Natural History of Chronic Obstructive Lung Disease in Working Men in London. New York, Oxford University Press, 1976.

26 Oga $T$, Nishimura $K$, Tsukino $M$, Sato $S$, Hajiro $T$, Mishima M. Exercise capacity deterioration in patients with COPD: longitudinal evaluation over 5 years. Chest 2005; 128: 62-69.

27 Redelmeier DA, Bayoumi AM, Goldstein RS, Guyatt GH. Interpreting small differences in functional status: the six minute walk test in chronic lung disease patients. Am J Respir Crit Care Med 1997; 155: 1278-1282.

28 Olsson LG, Swedberg K, Clark AL, Witte KK, Cleland JG. Six minute corridor walk test as an outcome measure for the assessment of treatment in randomized, blinded intervention trials of chronic heart failure: a systematic review. Eur Heart J 2005; 26: 778-793.

29 Agusti AG, Sauleda J, Miralles C, et al. Skeletal muscle apoptosis and weight loss in chronic obstructive pulmonary disease. Am J Respir Crit Care Med 2002; 166: 485-489.

30 Montes de Oca M, Torres SH, De Sanctis J, Mata A, Hernández N, Tálamo C. Skeletal muscle inflammation and nitric oxide in patients with COPD. Eur Respir J 2005; 26: 390-397. 